\title{
Suppressor-Effector T-Lymphocyte
}

National Cancer Institute

\section{Source}

National Cancer Institute. Suppressor-Effector T-Lymphocyte. NCI Thesaurus. Code C12544.

T-lymphocytes that respond to signals from suppressor-inducer T-cells by inhibiting either cell-mediated immunity or antibody production by B-cells. 